\title{
AWARENESS AND ATTITUDE TOWARDS STROKE AND ITS PREVENTION AMONG HYPERTENSIVE AND NON-HYPERTENSIVE PEOPLE
}

\author{
SREEJESH K P*, ATHIRA K S, HEYDEY GREEN M J \\ Department of Community Health Nursing, Amrita College of Nursing, Amrita Vishwa Vidyapeetham, Kochi, Kerala, India. Email: \\ sreejeshkp@aims.amrita.edu
}

Received: 15 September 2017, Revised and Accepted: 22 November 2017

\begin{abstract}
Objectives: objectives of the study are to compare the awareness and and attitude towards stroke and its prevention among hypertensives and nonhypertensives and compare the awareness and attitude towards stroke and its prevention among hypertensives and Non-hypertensives (2) to find out the association between the awareness and attitude toward stroke and its prevention with selected demographic variables among hypertensives and non -hypertensives.
\end{abstract}

Methods: Descriptive survey design was adopted for the study. Convenience sample technique was used to select 70 hypertensive and 70 nonhypertensive people at $1^{\text {st }}$ and $2^{\text {nd }}$ ward of Nayarambalam Panchayat, Ernakulam, Kerala. The data collection tool consists of a structured questionnaire to identify demographic data and awareness about stroke and prevention and five-point Likert scale to assess attitude toward stroke and its prevention. The datum was analyzed using descriptive and inferential statistics.

Results: Even though the mean awareness score of non hypertensives (11.9714) was relatively higher than the hypertensives (11.6286) there was no significant difference between them. Similarly, mean attitude score of hypertensive people (32.0286) was relatively higher than the non-hypertensive people (30.929) there was no significant difference between. There was significant association found between educational level of non-hypertensive people and awareness regarding stroke and its prevention and educational level of hypertensive people and attitude toward stroke and its prevention.

Conclusion: In conclusion of this study result shows that awareness regarding stroke and its prevention was average even among hypertensives so intense educational need for high-risk group.

Keywords: Awareness, Attitude, Stroke, Hypertension, Prevention of stroke.

(C) 2018 The Authors. Published by Innovare Academic Sciences Pvt Ltd. This is an open access article under the CC BY license (http://creativecommons. org/licenses/by/4. 0/) DOI: http://dx.doi.org/10.22159/ajpcr.2018.v11i3.22612

\section{INTRODUCTION}

Hypertension is a condition that affects 1 billion people worldwide and is a leading cause of morbidity and mortality. Hypertension is a condition in which systolic blood pressure (SBP) $\leq 140 \mathrm{~mm}$ of $\mathrm{Hg}$ and/or diastolic pressure $\leq 90 \mathrm{~mm}$ of Hgor on antihypertensive medication [1]. Worldwide hypertension is believed to cause 7.5 million deaths, about $12.8 \%$ of the total of all annual deaths [2]. In India, Customer Service Index Survey on 2015 covered 200,000 people across 24 states identified that one-third of the country's population suffers from hypertension and $60 \%$ of them are do not know about the condition [3]. Complication ofuntreated hypertension include ventricular hypertrophy,heart failure,accelerated atherosclerosis,cerebrovascular diseases and stroke,renal failure and retinopathy [4]. Stroke is one of the leading causes of death and disability in India. WHO defined stroke as rapidly developed clinical signs of focal disturbance of cerebral function; lasting more than $24 \mathrm{~h}$ or leading to death, with no apparent cause other than vascular origin [5]. Temporary disruption of the blood supply to part of the brain leads to transient ischemic attack or ministroke. The effects often only last for a few minutes or hours and fully resolve within $24 \mathrm{~h}$ [6]. According to the WHO (2011), cerebrovascular disease caused 6.1 million deaths, and it was considered $10 \%$ of all deaths in the world in 2008. Most of the mortality took place in the developing countries [7]. According to Indian Council of Medical Research report 2004 prevalence rates of cerebrovascular disease in India are about 1.54 per thousand and death rate for 0.6 per thousand around 597.6 per lac daily lost occurred [8]. Types of stroke are ischemic stroke and hemorrhagic stroke. There are two types of the risk factor. They are modifiable and non-modifiable risk factors. Non-modifiable risk factors are age, gender, race, ethnicity, and heredity. Potentially modifiable risk factors of stroke are hypertension, cardiac disease, diabetes and glucose metabolism, cigarette smoking, alcohol illicit, drug use, and various lifestyle factors such as obesity, physical inactivity, diet, and acute triggers such as emotional stress and oral contraceptives [9]. Hypertension is the most risk factor for stroke. Every $20 \mathrm{~mm} \mathrm{Hg}$ increase in SBP, doubling stroke risk [10]. Stroke recurrence can contribute to increased disability and disease burden. Control of modifiable risk factors was demonstrated reduce the risk of future stroke [11].

A prospective intervention study was conducted by Spurthi T., Gowthami B., Khyathi D, Vinod G regarding risk elements and drug utilization in stroke patients. The study conducted on stroke patients in Medicine Department, Viswabharathi Hospital, Kurnool, AP from January to September 2015. The sample size was 100 patients. The study revealed that the incidence of ischemic stroke (96\%) was greater compared to hemorrhagic stroke (4\%). $34 \%$ of the subject found to have $>3$ risk factors. Hypertension (68\%) was the common risk factors. Other risk factors were age (58\%), diabetes (39\%), smoking (22\%), alcoholism (21\%), and coronary artery disease $(10 \%)$. Other finding shows that $16.25 \%$ used anti-hypertensives followed by gastrointestinal agents (12.2\%), antiplatelet (9.6\%), hyperlipidemia (8.4\%), and nootropics (7.9\%) [12]. Sattanathan K, Chachu Kuriakose, Naseem Shifafiya M, Nelta S Tharakan, Sambath Kumar R conducted a prospective study of clinical profile of stroke in tertiary care hospital. The study is carried in a Shri Preethi Hospital for a period of 6 months (May 2015-October 2015).The study identified that out of 241 patients, an incidence of ischemic stroke was found to be higher. The occurrence of stroke steeply rises with age and male affected more compared to female. The burden of found to be more in rural, illiterate, and low socioeconomic status population. The study found the risk factors such as a sedentary lifestyle, previous and 
family history of stroke, and underlying disease such as hypertension and diabetes [13].

The presence of a serious and chronic illness in one family member usually has a profound impact on the family system, especially on its role structure and the family functions. Families have an important role during the course of a client's convalescence or rehabilitation. Most caregivers of stroke survivors find themselves in a stressful situation. A experimental study conducted by Hemamalini. M, A. Judie regarding the effect of psychosocial intervention on family system strengths among the caregivers of stroke survivors. The true experimental pre-test and post-test design study was conducted in Kattankulathur block, Tamil Nadu. The study included 240 caregivers of stroke survivors. The experimental group received psychosocial interventions such as individual counseling and enrollment in selfhelp groups. After 3 months, there was a significant difference in the family system strengths between the experimental group and control group at $\mathrm{t}=37.58$ and $\mathrm{p}=0.001$. This result shows that family coping intervention is an effective nursing intervention recommended for the caregivers of stroke survivors to strengthen family system [14]. A retrospective observational study conducted by Jithin KC, Arya G, Nair L P and Lakshmi R of the patterns of prescribing medications used in secondary prevention of stroke in 2015. Sample size of the study was 636 patients who are admitted to the hospital from July 1, 2014 to July 1, 2015 included in the study. The study finding disclosed that $21.7 \%$ had diabetes mellitus and hypertension as comorbidity and $21.35 \%$ had hypertension as comorbidity [15]. The warning signs of stroke are sudden numbness or weakness of face, arm or leg, especially on one side of the body, sudden confusion, sudden trouble speaking or understanding, sudden trouble walking, dizziness, loss of balance, and coordination, sudden severe headache with no known cause [16]. A hospital based case study conducted by Sangram Vurumadla, Rakshith V, Murari CH, Venkateshwarlu K about symptoms, risk factors and prescribing pattern of drugs used in stroke patients. The setting of the study was the Rohini multi-specialty hospital, Warangal, Telangana, and the study was carried out for a period of 7 months (February-August 2014 ) in the Department of Neurology. Out of 150 patients involved in the study, $100(66.66 \%)$ subjects presented with symptoms like slurred speech, followed by weakness on the right side in 97 (64.66\%) patients, headache in $88(58.66 \%)$ patients, change in speech in $87(58 \%)$ patients, weakness on the left side in $58(38.66 \%)$ patients, and deviation of mouth in $48(32 \%)$ patients. The most common risk factors associated with the stroke was hypertension in $102(68 \%)$ patients, followed by hyperlipidemia in $81(54.2 \%)$ patients, diabetes mellitus in $51(34.6 \%)$ patients, heart disease in 49 (32.6\%) patients, smoking in $44(29.3 \%)$ patients, diet in $16(10.6 \%)$, and alcohol in $12(8 \%)$ patients [17]. Every people should know the risk factors for stroke, warning signs of stroke and prevention of stroke and that awareness is very much needed among the hypertensive people. Awareness regarding stroke and its prevention helps to prevent the development of stroke. There are many studies conducted about the awareness about the stroke and its prevention. Most of the study revealed that people not adequately aware about the stroke and its prevention. A nonexperimental descriptive study conducted by Muhammad Rashid Amen to assess hypertensive patients' knowledge about lifestyle risk factors and warning signs of stroke. Purposive sampling technique used for the study and sampling size was 114 hypertensive patients. The study conducted among the patients who were admitted in Sulaimani City from February to April 2015. The study finding revealed that the mean knowledge for total stroke warning signs was very poor $(27.3 \pm 26.3)$. Only 55.3\% subjects had knowledge regarding the risk factors for stroke. The patients' knowledge was influenced by patients' age, gender, education levels, and duration of hypertension (p>0.05) [18]. Mark Kaddumukasa et al. conducted a descriptive cross-sectional survey to assess the knowledge, attitude and perception of stroke in rural and urban Uganda. The sample size of the study was 377 . No one identifies cigarette smoking as a risk factor of stroke and most of the subjects $(77 \%)$ did not know about the organ affected by stroke [19]. The present study conducted to assess the awareness and attitude of hypertensive and non-hypertensive regarding stroke and its prevention among selected ward of Nayarambalam Panchayat, Ernakulam, and give them adequate teaching in future it is needed.

\section{METHODS}

A quantitative approach with non-experimental comparative survey design was used for this study. The area selected for the study was $1^{\text {st }}$ and $2^{\text {nd }}$ ward of Nayarambalam Panchayat. 140 samples selected using non-probability convenience sampling technique, equally divided into hypertensives and non-hypertensives. Data were collected for a period of 2 weeks from January 1 to January 14, 2017. The data collection tool consists of a structured questionnaire to identify demographic data and awareness and five-point Likert scale to assess attitude toward stroke and its prevention. Demographic data included age, sex, marital status, educational status, occupation, and monthly income. Awareness assessed with 20 questions and includes the part such as general aspects of stroke, risk factors, and prevention. Attitude toward stroke and its prevention assessed with 10 statements. Attitude statements were equally divided into positive and negative statements. Descriptive statistics were used for the study was frequency percentage mean and standard deviation. Inferential statistics utilized for the study were independent $t$-test and Chi-square test. Approval was obtained the Research Committee of Amrita College of Nursing Scientific Committee and Ethical Committee of AIMS. Permission to conduct the study has been obtained from the Nayarambalam Panchayat. Informed written consent was taken from the participants before the commencement of the study.

\section{RESULTS}

Regarding the age of hypertensive people $52.9 \%$ and $38.6 \%$ belong to 51-60 years and $41-50$ years, respectively, whereas the age of nonhypertensive people $42.9 \%$ and $27.1 \%$ belong to $20-30$ years and $51-$ 60 years, respectively. Out of 140 samples, 47 (67.1\%) in hypertensive people and 37 (52.9\%) non-hypertensive people were females. About the educational status $48(68.6 \%)$ subjects in hypertensive people and $30(42.3 \%)$ subjects in non-hypertensive people were having the secondary level education. Regarding occupational status 38 (54.3\%) subjects were unemployed in hypertensive people whereas 34 (48.6\%) subjects were private employee, and 29 (41.4\%) were unemployed in non-hypertensive people. Majority of subjects, 50 (71.4\%) subjects in hypertensive people and $60(85.7 \%)$ subjects in non-hypertensive people were having monthly income of 1001-5000 Rs. The table also shows that most of the subjects, $68(97.1 \%)$ were married in the hypertensive people. At the same time, 61 (87.1\%) were married in non-hypertensive people.

Fig. 1 illustrates that the majority of hypertensive people 63 (90.0\%) had average awareness regarding stroke and its prevention. Majority of non-hypertensive people 64 (91.4\%) had average awareness regarding stroke and its prevention.

Fig. 2 depicts that majority of hypertensives 45 (64.3\%) had favorable attitude toward stroke and its prevention whereas favorable attitude toward stroke is equal in non-hypertensive.

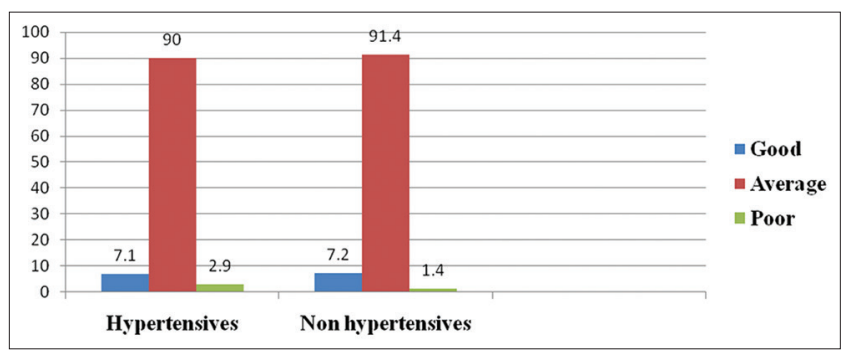

Fig. 1: Awareness of hypertensive and non-hypertensive people toward stroke and its prevention. 
Table1 summarizes the comparison of mean awareness level between hypertensive and non-hypertensive group. Table 1 summarizes that mean awareness score of non-hypertensive people $(11.9714 \pm 1.90)$ was relatively higher than the mean awareness score of hypertensive people (11.6286 \pm 1.96$)$. As calculated test statistics value 1.049 was lower than the table value 5.99 . Hence, the awareness score was not significantly more in non-hypertensive people compared to hypertensive people.

Table 2 summarizes comparison of mean attitude level between hypertensive group and non-hypertensive group. From Table 2, it is clear that mean attitude score of hypertensive people (32.0286 \pm 3.6 ) was relatively higher than the mean attitude score of non-hypertensive $(30.929 \pm 3.7)$

As calculated test statistics value 1.753 was lower than the table value 5.99 . Hence, the attitude score was not significantly more in hypertensive people compared to non-hypertensive people.

Table 3 summarizes the association awareness toward stroke and its prevention among non-hypertensive people with selected demographic

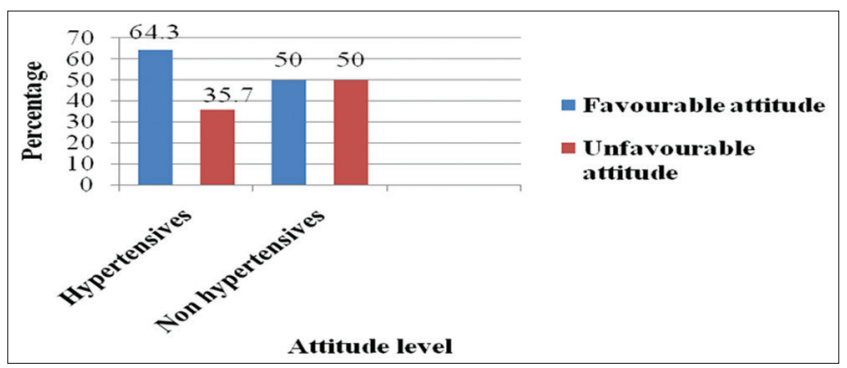

Fig. 2: Awareness of hypertensive and non-hypertensive people toward stroke and its prevention

Table 1: Comparison of awareness toward stroke in hypertensive and non-hypertensive people $(n=140)$

\begin{tabular}{lllll}
\hline Subjects & $\mathbf{n}$ & Mean \pm SD & $\mathbf{t}$ & $\mathbf{p}$ \\
\hline Hypertensives & 70 & $11.6286 \pm 1.96470$ & 1.049 & $0.296 \mathrm{~ns}$ \\
Non hypertensives & 70 & $11.9714 \pm 1.90325$ & & \\
\hline
\end{tabular}

$\mathrm{t}$ (138)=1.96, ns: Not significant. SD: Standard deviation

Table 2: Comparison of attitude toward stroke and its prevention among hypertensive and non-hypertensive people $(n=140)$

\begin{tabular}{lllll}
\hline Subjects & $\mathbf{n}$ & Mean \pm SD & $\mathbf{t}$ & $\mathbf{p}$ \\
\hline Hypertensives & 70 & $32.0286 \pm 3.60$ & 1.753 & $0.082 \mathrm{~ns}$ \\
Non-hypertensives & 70 & $30.929 \pm 3.73$ & & \\
\hline
\end{tabular}

$\mathrm{t}(138)=1.96$, ns: Not significant. SD: Standard deviation variables. There was a significant association $\left(\chi^{2}=5.49\right)$ at the level of $\mathrm{p} \leq 0.05$ significance between education and awareness score. There was no significant association with other demographic variable.

Table 4 summarizes the association between attitude toward stroke and its prevention among hypertensive people selected demographic variables. There was a significant association $\left(\chi^{2}=10.34\right)$ at the level of $\mathrm{p} \leq 0.05$ significance between education and awareness score. There was no significant association with other demographic variable.

\section{DISCUSSION}

The present study was aimed to determine the awareness and attitude toward stroke among hypertensive and non-hypertensive people residing in selected ward of Nayarambalam panchayat Ernakulum and also find the association between the awareness between hypertensive people and non-hypertensive people and association between the attitude toward the hypertensive and non-hypertensive people with selected variables. The study finding revealed that mean awareness score of non-hypertensive people $(11.97 \pm 1.96)$ was more than the mean awareness score of hypertensive people $(11.63 \pm 1.90)$ but no significant difference between them. Mean attitude score of hypertensive people $(32.03 \pm 3.6)$ was more than non-hypertensive people $(30.93 \pm 3.73)$ but no a significant difference between them. In this study, there was significant association found between education and awareness toward stroke ( $\mathrm{p}=0.026)$ and its prevention among nonhypertensive people. And also between education and attitude toward the stroke and its prevention among hypertensive people ( $\mathrm{p}=0.035)$. The present study result is contradictory with the study results of Venkatesh U Srivastava DK. A similar cross-sectional comparative study conducted to assess the knowledge, attitude, and practice in relation to stroke among hypertensive and non-hypertensive patients attending tertiary care center in Gorakhpur, Uttar Pradesh, in 2016. The mean score in Knowledge score of hypertension patient was more than non-hypertensive patient. The mean score in hypertensive patients was $1.991 .99 \pm 0.86$ and $1.91 \pm 0.96$ in non-hypertensive patients. Mean attitude score of the hypertensive patient was $9.22 \pm 2.34$ whereas in non-hypertensive patients were $18.79 \pm 2.11$ [20]. As our study, there was no significant difference between hypertensive and non-hypertensive group regarding on the awareness and attitude toward stroke and its prevention. The researcher also found that the awareness regarding stroke and its prevention was moderately adequate in both the group. Even though the mean awareness score of non-hypertensive (11.9714) was relatively higher than the hypertensive (11.6286), there was no significant difference between them. Similarly, mean attitude score of hypertensive people (32.0286) was relatively higher than the non-hypertensive people (30.929) there was no significant difference between. Most (90\%) people had average awareness regarding stroke and its prevention, and only $2.9 \%$ had poor awareness in hypertensive group similarly descriptive study conducted by Sahbanathul Missiriya, Johncey John about the prevalence of hypertension and knowledge regarding stroke. The study finding was that among the total number of people (1248) surveyed, 476 (38.1\%) were suffering from hypertension. They randomly selected 60 people

Table 3: Association between the awareness toward stroke and its prevention among non-hypertensive people and selected demographic variables $(n=70)$

\begin{tabular}{llllll}
\hline Demographic variables & \multicolumn{3}{l}{ Awareness f (\%) } & & \\
\cline { 2 - 6 } & Poor & Average & Good & df & $\chi^{\mathbf{2}}$ \\
\hline Education & $0(0)$ & $0(0)$ & $0(0)$ & & \\
Illiteracy & $0(0)$ & $0(0)$ & $0(0)$ & & \\
Primary & $0(0)$ & $28(93.3)$ & $2(6.7)$ & & \\
secondary & $0(0)$ & $26(89.7)$ & $3(10.3)$ & 8 & \\
Higher secondary & $1(20)$ & $4(80)$ & $0(0)$ & & \\
Diploma & $0(0)$ & $6(100)$ & $0(0)$ & & \\
Graduate & $0(0)$ & $0(0)$ & $0(0)$ & & \\
Postgraduate & & &
\end{tabular}

*Significant at $\mathrm{p} \leq 0.05$ 
Table 4: Association between the attitudes toward stroke and its prevention among hypertensive people and selected demographic variables $(n=70)$

\begin{tabular}{|c|c|c|c|c|c|}
\hline \multirow{2}{*}{$\begin{array}{l}\text { Demographic } \\
\text { variables }\end{array}$} & \multicolumn{5}{|l|}{ Attitude f (\%) } \\
\hline & $\begin{array}{l}\text { Unfavorable } \\
\text { attitude }\end{array}$ & $\begin{array}{l}\text { Favorable } \\
\text { attitude }\end{array}$ & df & $\chi^{2}$ & $\mathbf{p}$ \\
\hline \multicolumn{6}{|l|}{ Education } \\
\hline Illiteracy & $0(0)$ & $0(0)$ & & & \\
\hline Primary & $1(20)$ & $0(0)$ & & & \\
\hline Secondary & $23(47.9)$ & $28(93.3)$ & & & \\
\hline $\begin{array}{l}\text { Higher } \\
\text { secondary }\end{array}$ & $1(8.3)$ & $26(89.7)$ & 4 & 10.34 & $0.035^{*}$ \\
\hline Diploma & $0(0)$ & $4(80)$ & & & \\
\hline Graduate & $0(0)$ & $6(100)$ & & & \\
\hline Postgraduate & $0(0)$ & $0(0)$ & & & \\
\hline
\end{tabular}

*Significant at $\mathrm{p} \leq 0.05$

with hypertension [21]. Contradictory to our study most of the subjects $47(78.3 \%)$ had inadequate knowledge, 13 (21.7\%) had moderate knowledge, and none of them had adequate knowledge regarding prevention of stroke.

\section{CONCLUSION}

The present study revealed that awareness regarding stroke and its prevention was average in both hypertensive and non-hypertensive people and relatively low in hypertensives compared to nonhypertensive group. The awareness regarding stroke and its prevention is very essential in public especially among the hypertensives to prevent the development of stroke among them.

\section{AUTHORS' CONTRIBUTIONS}

Mr. Sreejesh KP - Review of literature and Data analysis. Ms. Athira KS Data Collection. Ms. Heydey Green -Data Collection.

\section{CONFLICT OF INTEREST}

No conflict of interest in this study.

\section{REFERENCES}

1. Lewis SL, Heitkemper MM, Dirksen SR, Obrien PG, Bucher L. Medical Surgical Nursing. $7^{\text {th }}$ ed. Noida, U.P: Elsevier Publishers; 2009.

2. Raised Blood Pressure. Global Health Observatory (GHO) Data; 2010. Available from http://www.who.int/gho/ncd/risk factors/ bloodpressures prevalence text/en. [Last cited on 2016 Nov 22].

3. Perappadan BS. $60 \%$ of Indians Unaware They are Suffering from High BP. The Hindu; 2015. September 26; Section.A:2 (Col 4).

4. Biswas S, Dastidar DG, Roy KS, Pal SK, Biswas TK, Ganguly SB. Complications of hypertension as encountered by primary care physician.J Indian Med Assoc 2003;101:4. Available from :http://www. ncbi.nlm.ih.gov/m/pubmed. [Last cited on 2018 Jan 11].

5. Park K. Text Book of Preventive and Social Medicine. $23^{\text {rd }}$ ed. Jabalpur: M/S Bhanot Publishers; 2015.

6. Transient Ischemic Attack. American Heart Association. Available from: http://www.strokeassociation.org/STROKEORG/AboutStroke/
TypesofStroke/TIA/Transient-Ischemic-Attack-TIA UCM 492003 SubHomePage.jsp. [Last cited on 2016 Nov 28].

7. Truelsen T. Global Burden of Cerebrovascular Disease; 2011; Available from: http://www.who.int.healthinfo/statistics/bodcerebrovasculardisease. pdf. [Last cited on 2016 Nov 02].

8. Assessment of Burden of Non Communicable Diseases. ICMR Final Report; 2004. Available from: http:/www.icmr.nic.in/annual/ icmrhq2004-05/Non-Communicable\%20Diseases.pdf. [Last cited on 2016 Nov 25]

9. Ralp L, et al. Public health burden of stroke. Stroke 1997;28:1507-17 Available from: http://www.stroke.ahajournals.org. [Last cited on 2016 Dec 13].

10. Blood Pressure and Cardiovascular Disease. The Seventh Report of the Joint National Committee on (Prevention, Detection, Evaluation, and Treatment of High Blood Pressure); 2004. Available from: https://www. ncbi.nlm.nih.gov/books/NBK9634. [Last cited on 2016 Dec 21].

11. Annie J, James E, Nambiar V. Impact of clinical pharmacist's interventions on health outcomes in post stroke patients. Int J Pharm Res 2015;7:38-43.

12. Spurthi T, Gowthami B, Khyathi D, Vinod G. Risk elements and drug utilization in stroke patients. Int J Pharm Pharm Sci 2016;8:290-2. Available from: https://www.innovareacademics.in/journals/index.php/ ijpps/article/view/128707406. [Last cited on 2017 Oct 19].

13. Sattanathan K, Kuriakose C, Shifafiya MN, Tharakan NS, Kumar RS. A prospective study of clinical profile of stroke in tertiary care hospitals. Asian J Pharm Clin Res 2016;9:1. Available from: https://www. innovareacademics.in/journals/index.php/ajpcr/article/view/13622. [Last cited on 2017 Oct 19].

14. Hemamalini M. A judie psycho social intervention - An effective strategy in improving the family system strengths among the caregivers of stroke survivors. Int J Pharm Clin Res 2014;6:336-40. Available from: https://www.ijpcr.com. [Last cited on 2017 Nov 14].

15. Jithin KC, Arya G, Nair LP, Lakshmi R. A study on pattern of prescribing medications used in secondary prevention of stroke. Asian J Pharm Clin Res 2016;9:328-30.

16. Stroke Warning Signs and Symptoms. American Heart Association; 2014. Available from http://www.strokeassociation.org/STROKEORG/ Warningsigns-/Stroke-Warning-Signs-and Symptoms. [Last cited on 2016 Nov 29].

17. Vurumadla S, Rakshith V, Murari CH, Venkateshwarlu K. Symptoms, risk factors and prescribing pattern of drug utilization in stroke patients. Int J Pharm Pharm Sci 2016;7:1. Available from: https:// www.innovareacademics.in/journals/index.php/ijpps/article/ view/3857/7647. [Last cited on 2017 Oct 21]

18. Amen MR. Assessment of hypertensive patients' knowledge about lifestyle risk factors and warning signs of stroke. Contemp Med Sci 2016;5:28-32. Available from: http://www.jocms.org/index.php/jcms/ article/view/64. [Last cited on 2017 Jun 26].

19. Kaddumukasa M, Kayima J, Kaddumukasa MN, Ddumba E, Mugenyi L, Pundik S, et al. Knowledge, attitude and perception of stroke in rural and urban Uganda BM res notes. 2015;5;819-22. Available from: https:/www.hindawi.com/journals/isrn/2014/309106/. [Last cited on 2017 Jun 14].

20. Venkatesh U, Srivastava DK. Knowledge, attitude and practice in relation to stroke among hypertensive and non-hypertensive patients attending tertiary care centre in Gorakhpur, Uttar Pradesh. J Med Sci Clin Res 2016;4. Available from: http://www.jmscr.igmpublication.org/ home/index.php/current-issue/1. [Last cited on 2017 May 27].

21. Missiriya S, John J. Prevalence of hypertension and knowledge regarding stroke. Asian J Pharm Clin Res 2017;10. Available from: http://www. innovareacademics.in/Journals. [Last cited on 2017 Oct 21]. 